\title{
REVIEW
}

\section{The new stem cell biology: something for everyone}

\section{S L Preston, M R Alison, S J Forbes, N C Direkze, R Poulsom, N A Wright}

J Clin Pathol: Mol Pathol 2003;56:86-96

The ability of multipotential adult stem cells to cross lineage boundaries (transdifferentiate) is currently causing heated debate in the scientific press. The proponents see adult stem cells as an attractive alternative to the use of embryonic stem cells in regenerative medicine (the treatment of diabetes, Parkinson's disease, etc). However, opponents have questioned the very existence of the process, claiming that cell fusion is responsible for the phenomenon. This review sets out to provide a critical evaluation of the current literature in the adult stem cell field.

See end of article for authors' affiliations

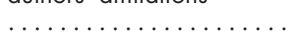

Correspondence to: Dr SL Preston, Department of Histopathology, Cancer Research UK, 44 Lincoln's Inn Fields, London WC2A 3PX, UK; sean.preston@cancer.org.uk

Accepted for publication 20 November 2002
T here is currently great excitement and expectation in the stem cell community. This originates from the discovery that pluripotent stem cells can be cultured from human fetal tissue and retain their ability to give rise to a variety of differentiated cell types found in all three embryonic germ layers. ${ }^{1}$ These embryonic stem (ES) cells, first isolated in 1981, are derived from the inner cell mass of the blastocyst and fetal gonadal tissue. Although this opens up the enticing possibility of "designer" tissue and organ engineering, it is clouded by the ethical issues that surround the use of these cells harvested from early human embryos.

Those who believe therapeutic cloning to be immoral have championed an important recent milestone, namely adult stem cell plasticity-the realisation that adult stem cells are not in fact lineage restricted. It is now believed that these cells are able to give rise to other cell types in a new location, not normally present in their organ of origin, in addition to their usual progeny in their organ of residence. Some have claimed that because adult stem cells can be induced to differentiate into multiple cell lineages, ES cells from blastocysts and aborted fetuses will no longer be needed. The concept of plasticity also raises the possibility of repairing an individual's failing organ by transplanting-for example, autologous bone marrow stem cells to replace their diseased liver. Although this has been shown to be possible in a mouse model, ${ }^{2}$ there is a long way to go before this technology can be applied to humans.

Some multipotential adult stem cells can cross lineage boundaries (transdifferentiate) when they have been relocated, making other specialised cells appropriate to their new niche. Bone marrow stem cells are particularly flexible and are able to contribute usefully to several recipient organs, notably the liver and myocardium, rescuing animals from genetic defects and organ damage. Some have argued that the phenomenon should occur "naturally" in undamaged organs before accepting stem cell plasticity. A counter argument is that organ damage is essential to allow transdifferentiation to occur at recognisable levels: it is largely in the clinical context of severe organ damage that one would envisage exploiting stem cells with transdifferentiating potential. Several studies have challenged the concept of stem cell plasticity. Issues have included the inability to reproduce data and, most notoriously, the suggestion that some apparently reprogrammed adult cells could really be engrafted cells fusing with cells in their new location. This is based on co-culturing bone marrow with highly volatile ES cells, not adult stem cells, and noting occasional tetraploid cells resulting from the fusion of the two cell types. There is no evidence from in vivo experiments that cell fusion occurs; moreover, impressive data are now emerging that selected bone marrow cells are extremely malleable and can be coaxed in vitro into many tissues. These are early days in the field of adult stem cell plasticity experimentation, and although many of the data have not shown that engrafted cells are clonogenic and produce functional progeny in their new location, a growing body of evidence indicates that certain haemopoietic stem cells have considerable potential in the treatment and repair of several vital organs.

This review summarises the rapidly developing field of stem cell research, paying particular attention to stem cell plasticity and some of the possible clinical roles in both malignant and nonmalignant disease.

\section{WHAT ARE STEM CELLS?}

Stem cells should possess two characteristic features: first, they must be able to renew themselves and, second, they must have the capacity for multilineage differentiation, as shown by clonal marker studies. ${ }^{3}$ However, stem cells have varying degrees of potential. This ranges from the totipotency (ability to form the embryo and the trophoblast of the placenta) of the fertilised oocyte (the zygote), to the pluripotency (ability to differentiate into almost all cells that arise from the three germ layers) of ES cells, to the multipotentiality (capability of producing a limited range of differentiated cell lineages appropriate to their location) of most tissue based stem cells, and lastly to the unipotentiality (only able to generate one cell type) of cells such as the

Abbreviations: CNS, central nervous system; ES, embryonic stem; $\mathrm{FAH}$, fumarylacetoacetate hydrolase; G-CSF, granulocyte colony stimulating factor; HSC, haemopoietic stem cell; ISEMF, intestinal subepithelial myofibroblasts; KGF, keratinocyte growth factor; MSC mesenchymal stem cell 


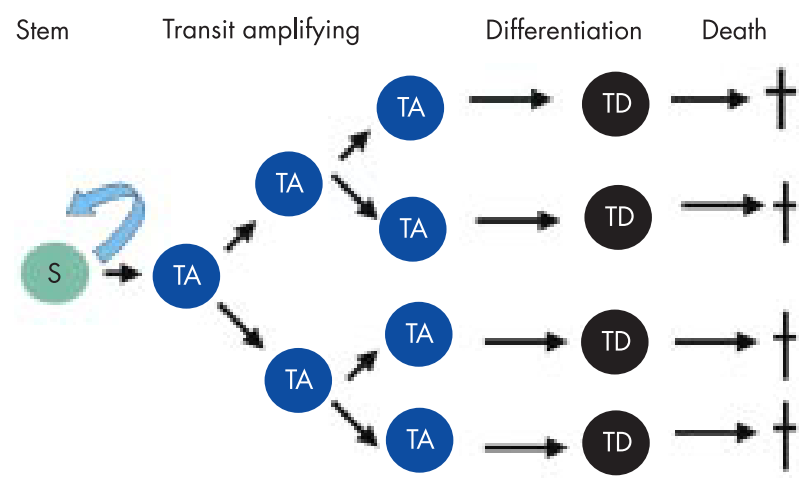

Figure 1 A hierarchy of stem cell potential. Stem cell(s) can divide asymmetrically to maintain their number while giving rise to transit amplifying cells (TA), whose functional capacity evolves concomitantly with a reduction in division potential. Eventually, TA cells become terminally differentiated (TD) and are programmed to die in a tissue specific manner.

epidermal stem cells and the spermatogonial cells of the testis. Between the stem cell and its terminal progeny there are usually several intermediate cells of increasing commitment. These are known as transit amplifying cells. Stem cells are relatively undifferentiated, and in most tissues are not able to carry out the specialist functions of the progeny to which they give rise. Early research concentrated on the haemopoietic stem cells (HSCs) of the bone marrow, and these are well characterised, ${ }^{5}$ but stem cells are now known to exist in most organs of the body, with the possible exception of the heart. In most tissues, stem cells form a minority population, usually only $1-2 \%$ or less of the total cellularity.

Self renewal is necessary if an organ or tissue is to survive continued insult-from simple cell shedding to the likes of xenobiotic and ischaemic injury. Many different types of stem cells are needed to survive the lifetime of an animal. Through asymmetric divisions, adult stem cells are able to produce just the right number of differentiated cells, in addition to daughter stem cells, with identical properties to the cell from which they were derived. Within a population, stem cell numbers are maintained by a probability of self renewal of 50\% (fig 1). This could be achieved by each stem cell always undergoing asymmetric division. Under conditions of no excess stress the stem cells are slow cycling, and in the bone marrow only about $10 \%$ are in the cell cycle at one time. This acts as a mechanism to protect the cells from errors that are prone to occur in the process of DNA synthesis. Other mechanisms appear to be present in intestinal stem cells: it has been reported that some of their DNA is present in immortal strands (that is, the same template DNA strands stay together through successive divisions), therefore avoiding the accumulation of replication errors in the stem cell genome. ${ }^{6}$

\section{THE STEM CELL NICHE}

Several theories have been proposed to explain the methods of lineage determination: extrinsic (through growth factors, stroma, or external influences), intrinsic (for example, nuclear factors), or both. Much emphasis is currently being placed on the environment in which a stem cell is placed-its "niche". A niche is a subset of tissue cells and extracellular substrates, which in vivo favours the existence of the stem cell in the undifferentiated state. The three dimensional environment in which the cell resides supports and controls its self renewal and progeny production. Interaction with other cell types and the components of the extracellular matrix are believed to

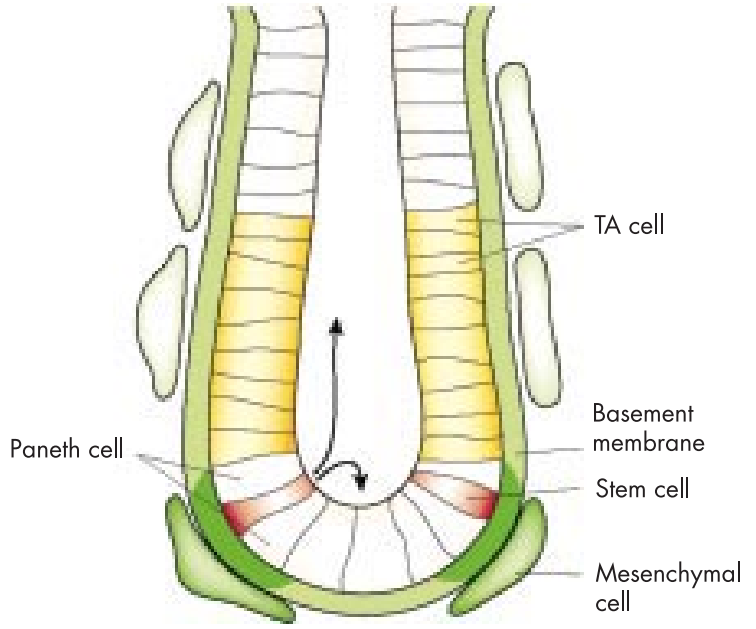

Figure 2 A mammalian gut crypt is a tube of cells arrayed on a basement membrane (green). Stem cells (red) are located in the basal region along with Paneth cells, but their exact location is variable and both types account for only a fraction of the cells present in the regions shown. A portion of the basement membrane in the stem cell region may be specialised (dark green). Stem cell progeny (yellow) known as transit amplifying (TA) cells move upwards and differentiate. Underlying mesenchymal cells (green) send signals that help regulate stem cell activity. (Reprinted by permission from Nature. ${ }^{10}$ Copyright (2001), Macmillan Publishers Ltd.)

influence the survival and development of the committed cells. One of the most studied receptors in the extracellular matrix is $\beta 1$ integrin, the high expression of which might be needed to maintain epidermal stem cells. Integrins hold the cells in place, and in their absence cells leave the niche through either differentiation or apoptosis. ${ }^{7-9}$ It appears that ultimately the ability of a cell to remain in the undifferentiated state, proliferate, or differentiate depends upon the expression of several transcription factors within it. These may arise from either intrinsic or extrinsic sources or, more probably, a combination of the two (that is, multiple positive and negative signals received through cytokines and other receptors stabilising a particular pathway).

"Ultimately the ability of a cell to remain in the undifferentiated state, proliferate, or differentiate depends upon the expression of several transcription factors within it"

A good example of a niche is in the small intestinal and colonic crypts (fig 2), where a steady, essentially unidirectional flow of cells from near the base of the crypts is required. The niche is formed by the base of the crypt itself and the surrounding, very closely applied mesenchymal cells-the pericryptal myofibroblasts. There is communication between the myofibroblasts and the crypt epithelial cells. Several growth factor genes are expressed by the stromal cells, although the receptors for the encoded growth factors are situated on the epithelial cells (for example, keratinocyte growth factor (KGF) and hepatocyte growth factor). On average, four to five stem cells are thought to reside near the base of each crypt. ${ }^{11}$ It has been shown that mice lacking the alleles for the HMG (high mobility group) box transcription factor Tcf-4 fail to maintain a proliferatively competent population of small intestinal crypts. ${ }^{12}$ This shows the necessity for positive signalling in the maintenance of the stem cell phenotype during the early stages of stem cell development.

The Wnt family of signalling proteins is also known to be important in the regulation of cell fate determination and cell 


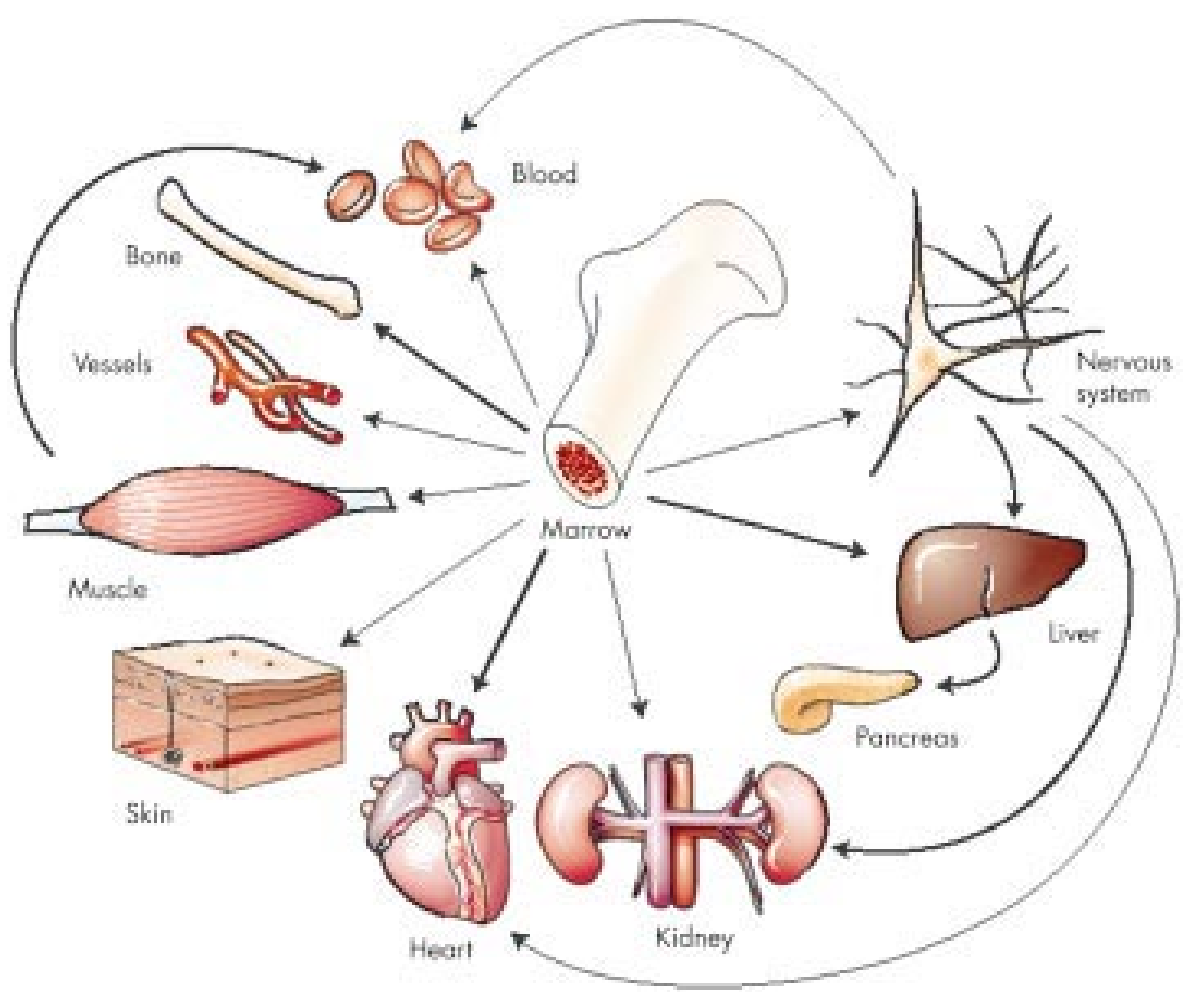

Figure 3 Possible pathways of differentiation in adult stem cells. (Reprinted with permission from Science. ${ }^{14}$ Copyright (2002), American Association for the Advancement of Science.)

proliferation, especially during embryonic development. The Wnt pathway uses a secreted signalling protein, a transmembrane protein, and complex intracellular machinery to relay signals from the cell surface to the nucleus. The signalling is dependent on the presence or absence of the intracellular protein $\beta$-catenin. When the signal is absent, the destruction complex (composed of axin, APC (the tumour suppressor protein encoded by the adenomatous polyposis coli gene), and glycogen synthase kinase $3 \beta$ ) marks $\beta$-catenin for destruction. When the signal is present, the destruction complex is deactivated, the concentrations of $\beta$-catenin then rise and $\beta$-catenin enters the nucleus and, via a DNA binding protein, activates expression of specific cassettes of target genes.

Throughout life, the number of niches has to increase to keep up with the increasing demands of both development and environmental stressors. Some, such as the crypts of the intestine, do this by branching and fission, whereas others have the capacity for de novo production. Niches are able to cope with the demand following the loss of particular cell types. $^{13}$

\section{STEM CELL PLASTICITY}

Until recently, it was believed that organ specific stem cells were lineage restricted. Recent work has questioned this, and proposed that adult stem cells may have much wider differentiation capabilities (fig 3). One of the first of these showed that bone marrow derived cells could target and differentiate into muscle. ${ }^{15}$ Others demonstrated apparent transdifferentiation of bone marrow into liver, kidney, cardiomyocytes, neural cell lineages, and gut. ${ }^{16-19}$ Contradicting some of the foundations of embryology, the phenomenon is not restricted to the origin of a cell in the embryologic trilayer, as shown by the reconstitution of bone marrow from cultured neurospheres. ${ }^{20}$ Most of this work has relied on the appearance of Y chromosome positive cells in a female recipient of a male bone marrow transplant in animals and humans. Markers such as LacZ and green fluorescent protein have also been used, usually in com- bination with lineage markers, to illustrate the switch in fate (transdifferentiation) of the transplanted cells.

However, there has been some scepticism regarding the validity of several of these techniques. The gold standard would be to show that a circulating stem cell not only engrafted in another organ and assumed the phenotypic traits of the resident cells, but also possessed the same multilineage potential and functional activity as them. Functionality has been the most difficult attribute to prove, but has been shown most convincingly by the rescue of mice with a potentially fatal metabolic liver disease. Here, following a bone marrow transplant the liver was repopulated with cells derived from the transplant. ${ }^{2}$

Anderson and colleagues have argued that claims for stem cell plasticity can only be made if the process can be shown to occur naturally using cells that have not been manipulated ex vivo before transplantation to organs that have not been damaged. ${ }^{21}$ This would be extremely difficult to do because any manipulation of either the host, the donor, or the cells themselves would be seen as "unnatural". The severe organ damage that is present in much of this work may be of particular importance when it is viewed in a clinical context.

Based on co-culture of ES cells with either bone marrow or neural stem cells, two recent publications have suggested that the previous experimental observations of adult stem cell transdifferentiation resulted from fusion of the bone marrow cells with the differentiated cells of the new organ. ${ }^{22}{ }^{23}$ Their speculations conflict with observations of-for example, postpartum thyroiditis ${ }^{24}$ : one female patient having had a male offspring had clusters of fully differentiated thyroid follicular cells bearing one $\mathrm{X}$ and one Y chromosome (fig 4). Accepting that the source of transdifferentiated cells was from the fetus and not a deliberate transplant, no follicular cells were XXXY, suggesting cell fusion was not responsible for the phenomenon. Another argument against fusion being responsible for apparent transdifferentiation comes from the recent in vitro work by Jiang et al. ${ }^{25}$ They demonstrated that single, euploid bone marrow derived multipotent adult progenitor cells could 


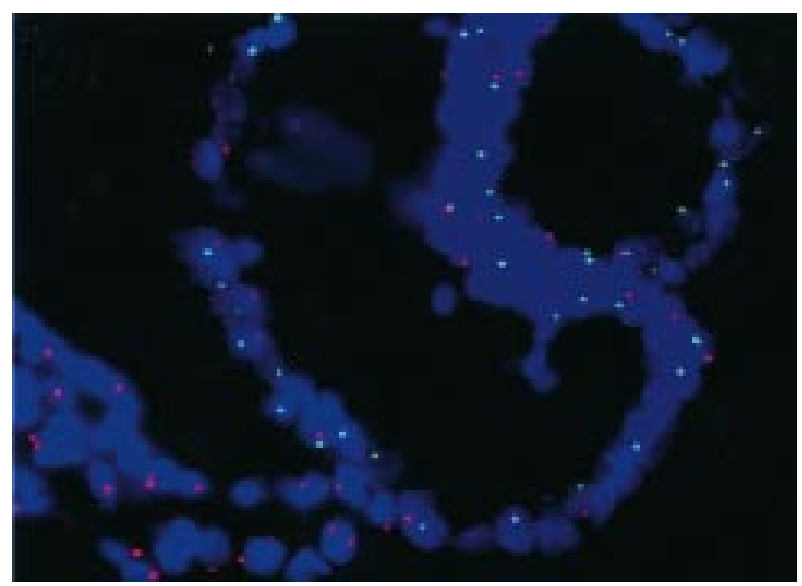

Figure 4 Photomicrograph of a thyroid section of a progressively enlarging adenomatous goitre, showing thyroid follicular nuclei after fluorescent in situ hybridisation analysis for the $X$ (red) chromosome and $Y$ (green) chromosome (original magnification, $\times 400$ ). Epithelial cells with $\mathrm{X}$ chromosomes only can be seen in the left hand corner, whereas in a single row of adjacent epithelial cells the cells have no more than one $X$ and one $Y$ chromosome. See text for further details (from Srivatsa et al, ${ }^{24}$ with permission).

differentiate into cells from all three germ layers. These cells had never been co-cultured with either embryonic stem cells or tissue specific stem cells, so it was not possible for fusion to have been responsible for the transition.

"Two recent publications have suggested that the previous experimental observations of adult stem cell transdifferentiation resulted from fusion of the bone marrow cells with the differentiated cells of the new organ"

\section{Bone marrow}

Bone marrow is a mesodermal derived tissue consisting of a complex haemopoietic cellular component supported by a microenvironment composed of stromal cells embedded in a complex extracellular matrix. ${ }^{26}$ It contains HSCs and mesenchymal stem cells (MSCs), which may both be derived from a common primitive blast-like cell. ${ }^{27}$

\section{Haemopoietic stem cells}

The HSC is the archetypal stem cell, from which much of our knowledge on stem cells has arisen. These cells are rare, comprising only $1 / 10000$ to $1 / 100000$ of total blood cells, and they appear to be the most versatile at crossing lineage boundaries. HSCs can be obtained from the bone marrow, peripheral blood, ${ }^{28}$ umbilical cord, ${ }^{29}$ and fetal liver. ${ }^{30}$ During development there is flux between the sites capable of supporting them. In the adult, this revolves around the bone marrow, with most transplanted HSCs returning to bone marrow cavities within one day. It has recently been established that integrins such as VLA-4 and other adhesion receptors such as CD44 are essential in stem cells homing to the bone marrow. Experiments involving switching off the receptor CXCR4 on bone marrow stem cells ${ }^{31}$ show that it is pivotal in this mechanism. The chemokine, stromal derived factor 1 , is produced by the bone marrow and binds to the CXCR4 receptor, thus activating various cell adhesion molecules through intracellular signalling. Another receptor thought to be involved in the process of homing and engraftment is c-Kit, which allows HSCs to adhere to the stroma via membrane bound stem cell factor.

Migration in the opposite direction can be encouraged experimentally using the cytokine granulocyte colony stimulating factor (G-CSF). In mobilising stem cells in this way, Levesque et al established that neutrophil derived proteases are able to cleave the predominant adhesion molecule and release stem cells from their niche. ${ }^{32}$

One of the most important steps in the evolution of stem cell research was the discovery that the sialomucin CD34 is a haemopoietic cell surface antigen. Because its expression is downregulated as the cells become more mature and more differentiated, CD34 has become the distinguishing feature in isolating, counting, and manipulating haemopoietic stem cells. Its function, however, remains unknown. A recent caveat to this story has been the publication of several studies suggesting that some HSCs do not express CD34.

Mesenchymal stem cells

MSCs have the capacity to differentiate, both in vivo and in vitro, into osteoblasts, chondroblasts, and adipocytes when exposed to the appropriate stimuli. They are adherent to tissue culture plastic.

Before a pure population of MSCs is used experimentally it must first be sorted and then cultured in vitro. It is possible that this manipulation may have an effect on the ultimate differentiated form that the cell takes. When MSCs are pre-exposed to 5-azacytidine they are capable of differentiating into skeletal and cardiac muscle phenotypes. ${ }^{33}$ Peripheral and direct injection of human MSCs has enabled these cells to integrate deep into rat brain, and to lose their markers of MSC

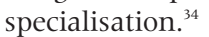

\section{Somatic sites of stem cell plasticity \\ Endothelium}

The endothelium of vessels is partially derived from circulating angioblasts. Lin et al examined the circulating endothelial cells of sex mismatched transplants, which had taken place five to 20 months earlier. ${ }^{35}$ They established that most endothelial cells in fresh, peripheral blood had a recipient genotype. When these same blood samples were cultured, the recipient genotype predominated at nine days, whereas after one month in culture the endothelial outgrowth was mainly donor derived. Because these cells had a more delayed outgrowth, but a higher proliferative rate, it was suggested that they must be derived from circulating angioblasts. In vitro, angioblasts derived from human peripheral blood have been shown to incorporate into sites of active angiogenesis in animal models of ischaemia, ${ }^{36}$ with important clinical implications.

Interestingly, when endothelial repopulation of grafted segments of aorta was studied, there was less engraftment when rejection was inhibited by immunosuppression. In its absence, up to $10 \%$ of the endothelium was found to be host derived, ${ }^{37}{ }^{38}$ indicating that tissue damage was a potent stimulus to engraftment of circulating cells. Recent work inducing myocardial infarcts in rats by ligating their left anterior descending artery has shown that adult human CD34 positive cells mobilised by G-CSF are able to participate in the reparative process. ${ }^{39}$ After an intravenous injection they are able to generate new human capillaries, principally through angioblastic precursors, within the infarct zone. Other work using infarcted rat heart ${ }^{18}$ found that, when highly purified rat Lin negative/c-kit positive cells were injected directly into the myocardium, new bone marrow derived endothelial cells were generated, in addition to cardiomyocytes and smooth muscle cells.

\section{Heart}

Several extracardiac sources of cells with myogenic potential have been reported. Unsurprisingly, one of those is the bone marrow. ${ }^{18}$ Malouf et al found that the rat liver was another source. $^{40}$ They clonally derived a cell line (WB-F344) from a young male rat liver and tagged it with the Escherichia coli lac Z gene. This cell line was then injected directly into the left ventricle of female nude mice, and after six weeks they showed 
cardiomyocyte differentiation. The cells, positive for the $\mathrm{Y}$ chromosome, were able to express cardiac troponin T, in addition to $E$ coli $\beta$-galactosidase.

Work in humans, using the $\mathrm{Y}$ chromosome as a marker, in sex mismatched cardiac transplants, has shown that a small proportion of cardiomyocytes, coronary arterioles, and capillaries were derived from the bone marrow. ${ }^{41}$ One of the most recent developments in this field is from a group of German investigators who published results from a series of patients, who at the time of myocardial infarction were treated by coronary angioplasty and injection of autologous bone marrow into their coronary arteries. They noted improvements in the physiological function of the myocardium, ${ }^{42}$ but no morphological analysis was performed to establish that the bone marrow had transdifferentiated into cardiomyocytes.

\section{Lung}

In the lung, the nature of the multipotential stem cells differs, depending on their location within the bronchopulmonary tree. In the proximal airways (trachea and bronchi) the basal cells appear to be the major source of proliferative cells. Further down in the terminal and respiratory bronchioles, Clara cells increase their proliferative rate in response to injury. ${ }^{43}$ The type II pneumocyte appears to be the stem cell in the alveoli, and is able to generate daughter cells that can differentiate into type I pneumocytes. A milestone paper in stem cell research was that of Krause et al, ${ }^{44}$ whose group used a single stem cell derived from male bone marrow (lineage depleted and enriched for CD34 positive and Sca-1 positive cells), injected it into a female recipient, supported by $2 \times 10^{4}$ haemopoietic progenitor cells, and demonstrated its differentiative capacity. The lung showed a high level of engraftment. At 11 months, $20 \%$ of the cytokeratin expressing alveolar pneumocytes were Y chromosome positive (many being type II cells). This surprisingly high number was attributed to either a viral infection and/or the pretreatment of the animals with a dose of potentially lethal irradiation.

\section{Gastrointestinal tract}

In the intestine, the multipotential stem cells are thought to be housed in the crypt base. The work carried out by Krause et al using a single stem cell (outlined above) demonstrated differentiation to epithelial cells throughout most of the gastrointestinal tract (oesophagus, stomach, and small and large bowel). Eleven months after the transplant, low level engraftment was shown $(0.19-1.81 \%$ of the cells within the gastrointestinal tract were donor derived), generally seen as randomly inserted single cells, although they did not show engraftment of the pericryptal sheath. However, Brittan et al showed that, in the context of a bone marrow transplant in mice, the donor cells were able to engraft both the small intestine and colon and differentiate into intestinal subepithelial myofibroblasts (ISEMFs) located in the lamina propria underneath the gastrointestinal mucosa (fig 5$).{ }^{45}$ As time progressed, the ISEMFs became present in columns, extending from the crypt base to the luminal surface, prompting the authors to suppose that they might be derived from an engrafted stem cell at the crypt base. They also noted, again using in situ hybridisation for the Y chromosome, that the ISEMFs in small bowel biopsies taken from female patients (suspected of graft versus host disease) were derived from the male bone marrow donor. Others have demonstrated reprogramming of mouse brain neural stem cells to contribute to the intestine ${ }^{46}$ whereas villus and cryptal epithelial cells in the duodenum have been derived from a population of highly clonogenic cells from mouse liver. ${ }^{47}$

\section{Liver}

The liver has a large regenerative capacity from hepatocytes, oval cells, and also the bone marrow. After two thirds hepatectomy, the remaining hepatocytes only have to cycle on aver-

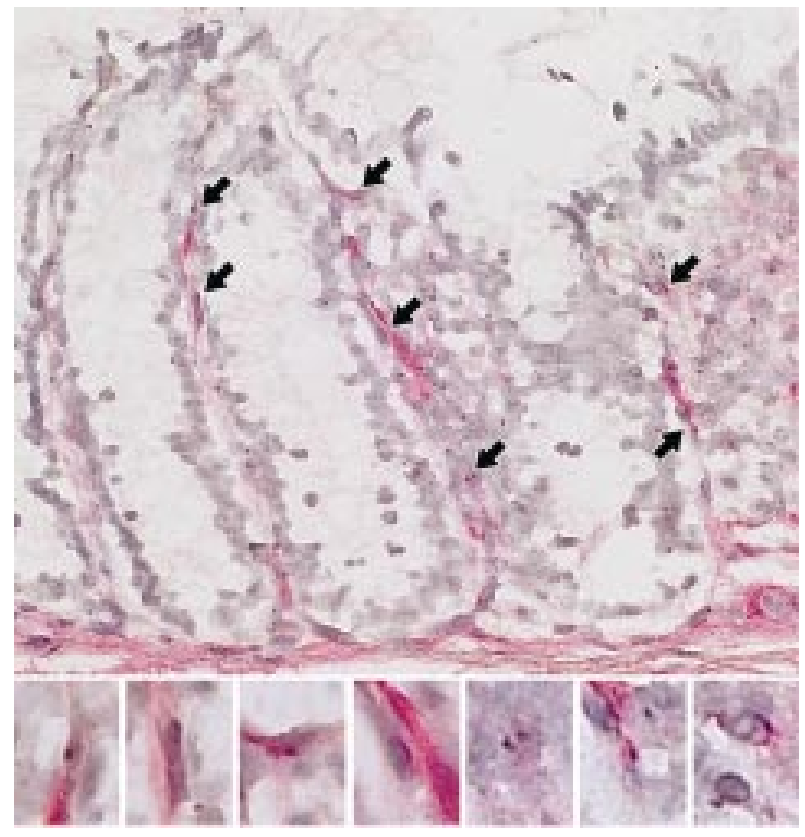

Figure 5 Bone marrow derived intestinal subepithelial myofibroblasts in the female mouse colon after male bone marrow transplantation are present as $Y$ chromosome positive cells, immunoreactive for $\alpha$ smooth muscle actin ( $\alpha S M A)$, two weeks after transplantation (arrows and high power insets). The $Y$ chromosome is seen as a brown/black punctate density; red cytoplasmic staining indicates immunohistochemical staining for $\alpha \mathrm{SMA}$ (from Brittan et $\mathrm{al}_{1}{ }^{45}$ with permission from the BM Publishing Group).

age 1.6 times to restore their preoperative cell number. In circumstances of prolonged liver damage or inhibition of hepatocyte regeneration the so called oval cells can act as facultative stem cells. ${ }^{48}$ Oval cells are located within the smallest branches of the intrahepatic biliary tree and are capable of amplifying the biliary population before they differentiate into hepatocytes.

"In one of the most convincing demonstrations of the therapeutic potential of bone marrow, haemopoietic stem cells have been shown to have functionality in the liver"

The liver was one of the original organs of interest in the field of plasticity. Petersen et al showed for perhaps the first time that it was possible for bone marrow derived cells to differentiate into epithelial cells of non-mesenchymal origin. ${ }^{49}$ They caused hepatic damage in female rats with carbon tetrachloride and inhibited hepatocyte regeneration with 2-acetylaminofluorene. Two weeks later, the donor derived Y chromosome was detectable within a small proportion of hepatocytes. This bone marrow-liver axis has also been demonstrated in humans in two ways, using the Y chromosome as a marker. ${ }^{1650}$ First, in the livers of female patients who had previously received a bone marrow transplant from a male patient; and second, in the female livers engrafted into male patients that were later removed because of recurrent disease. In both groups, $\mathrm{Y}$ chromosome positive hepatocytes were readily identified. Engraftment levels were highly variable, but appeared to be related to the severity of parenchymal damage. In one liver transplant recipient with recurrent hepatitis C, up to $40 \%$ of the hepatocytes and cholangiocytes were $\mathrm{Y}$ positive, suggesting that they were derived from circulating stem cells of recipient origin..$^{50}$

In one of the most convincing demonstrations of the therapeutic potential of bone marrow, HSCs have been shown to 

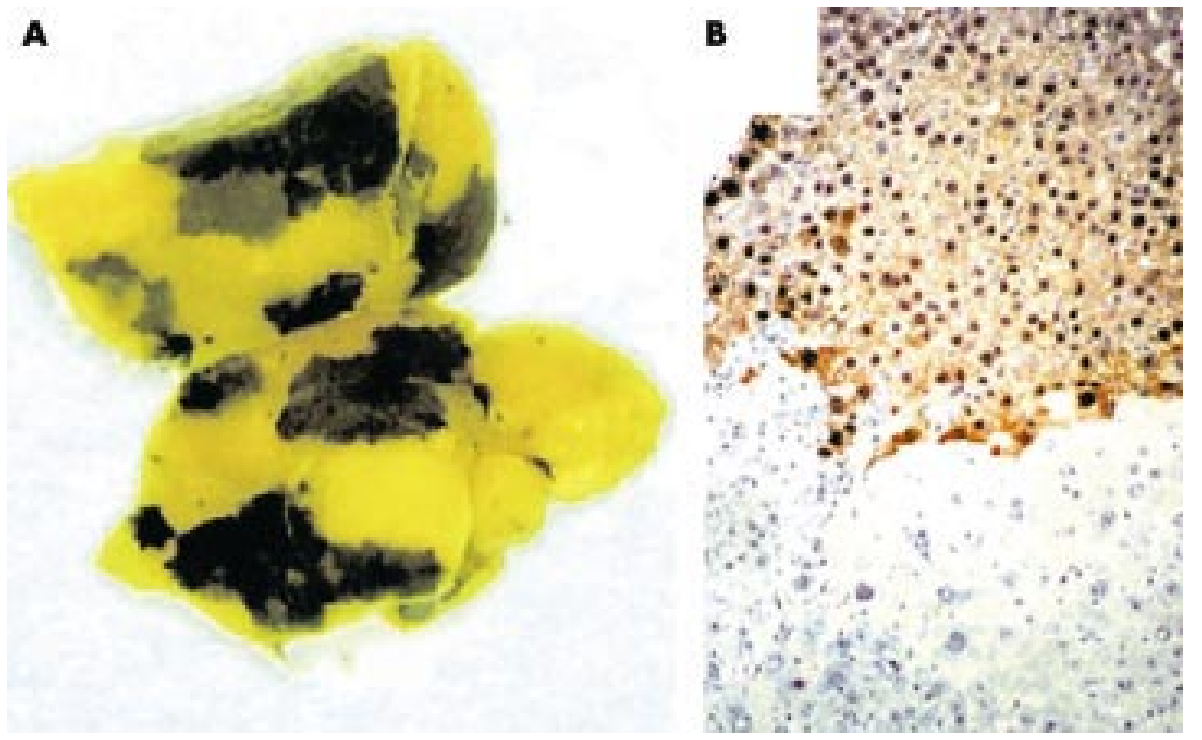

Figure 6 Liver histology of mice deficient in the enzyme fumarylacetoacetate hydrolase ( $\mathrm{FAH}^{-1}$ mice) seven months after bone marrow transplantation. $\mathrm{FAH}^{-/-}$mice were transplanted with $1 \times 10^{6}$ bone marrow cells from ROSA26 mice. (A) Repopulating nodules are detected in the liver with X-gal histochemistry. (B) FAH staining of the nodule. The dark red areas are FAH positive hepatocytes and are adjacent to an FAH negative area (from Lagasse et al, ${ }^{2}$ with permission).

have functionality in the liver. Female mice deficient in the enzyme fumarylacetoacetate hydrolase (FAH) (a model for fatal hereditary tyrosinaemia type 1) were transplanted with $10^{6}$ unfractionated bone marrow cells. ${ }^{2}$ These mice would usually suffer from progressive hepatic failure and renal tubular damage, and ultimately death, as a result of the accumulation of the metabolite fumarylacetoacetate and its precursor maleylacetoacetate. However, after the transplant, the bone marrow derived cells were able to reconstitute $30-50 \%$ of the liver mass, restore liver function, and keep the mice alive (fig 6). They also transplanted the female mice with highly purified HSCs, which gave rise to both donor derived haemopoietic cells and hepatocytes, with the HSC derived hepatocytes expressing the same hepatocyte markers as the bone marrow derived hepatocytes. In both this study and a subsequent report detailing the time course of this phenomenon, ${ }^{51}$ the HSC derived hepatocytes were located in distinct foci rather than diffusely scattered throughout the liver. This may represent multiple engraftment at selected sites, but more probably reflects rare engraftment events (approximately one within a million indigenous hepatocytes) and the subsequent clonal expansion of these engrafted cells under a strong and persistent positive selection pressure.

\section{Pancreas}

The pancreas has both exocrine and endocrine functions. One of its endocrine functions is glucose homeostasis, which is carried out by islet $\beta$ cells, and this is where most of the attention on the pancreas has been focused. These cells are a constantly renewing population and are supplied by the pancreatic duct cells. Bonner-Weir and colleagues ${ }^{52}$ established that all mature duct cells are potential stem cells, able to revert to their less differentiated form and from there expand and differentiate along different pancreatic lineages. Importantly, functioning islet cells have been generated in vitro from cultured pancreatic duct cells..$^{53}$

Because of the similar embryological origins of both the liver and the pancreas, it is not surprising that there is a degree of plasticity between the cells of the two organs. Krakowski et al generated insulin promoter regulated KGF transgenic mice, which, under the influence of KGF, developed numerous functional hepatocytes within the islets of Langerhans. ${ }^{54}$ Work with the aforementioned $\mathrm{FAH}^{-/}$mouse showed that although transplantation with pancreatic cells is not usually lifesaving, a small proportion of the animals can survive if $50-90 \%$ of the diseased liver is replaced by pancreatic derived hepatocytes. ${ }^{55}$

\section{Kidney}

The kidney has no recognised source of stem cells within it, but in spite of this, tubular cells are able to regenerate after injury. Reprogramming and differentiation of cells from other organs may have a part to play in this renewal. It has been shown that adult mouse neural stem cells injected into an early embryo are able to contribute to the developing kidney. ${ }^{46}$ Grimm et al examined renal biopsies from patients undergoing chronic rejection ${ }^{56}$ and found host derived mesenchymal cells (fibroblasts and myofibroblasts) within them, providing evidence for a circulating population capable of migrating to areas of inflammation. Poulsom et al, ${ }_{19}^{19}$ using in situ hybridisation for the Y chromosome in human transplant patients, showed that circulating stem cells were able to engraft the kidney and differentiate into renal parenchymal cells. In mice, they also showed bone marrow derived renal tubular epithelial cells, and within glomeruli, bone marrow derived cells that appeared to be podocytes. ${ }^{19}$ The work by Krause and colleagues ${ }^{44}$ provided some confounding data because they found no donor derived renal tubular epithelial cells. This may have been because they used HSCs and not whole bone marrow, which contains MSCs, as used by Poulsom et al. ${ }^{19}$

Epithelial-mesenchymal transdifferentiation may also occur in the diseased kidney, although it appears to be restricted to areas where there has been damage to the basement membrane, perhaps because factors on collagen type IV that are permissive for maintenance of the epithelial phenotype are lost. In a rodent model of progressive renal fibrosis there was evidence that epithelial cells were capable of transdifferentiating into myofibroblasts. ${ }^{57}$

\section{Nervous system}

Central nervous system (CNS) stem cells have trilineage ability-they can generate neurones, oligodendrocytes, and astrocytes. It has been established in rodents that when the neural plate first develops it contains a high proportion of neural stem cells. As the embryo develops, the frequency of these cells declines as they are diluted by daughter cells..$^{58}$ Adult neural stem cells have been found both in the 
hippocampus and the subventricular zone. ${ }^{60-62}$ They are capable of forming cells of all three germ layers and divide in response to epidermal growth factor and fibroblast growth factor, ${ }^{63}$ as shown by Palmer et al ${ }^{64}$ who isolated cells capable of forming astrocytes and neurones from human postmortem tissue.

\section{"Central nervous system stem cells have trilineage ability-they can generate neurones, oligodendrocytes, and astrocytes"}

One of the earliest studies to show a degree of plasticity within neural stem cells illustrated that stem cells derived from the adult spinal cord, which do not normally produce neurones, could be induced to do so when injected into the adult hippocampus ${ }^{65}$ A greater degree of plasticity appeared to be possible when it was reported that neurosphere cells derived from single neuronal stem cells were able to transdifferentiate into several haemopoietic lineages. ${ }^{20}$ However, an attempt to repeat these observations using the same protocol failed to show haemopoietic differentiation. ${ }^{66}$ The inference taken from this was that transdifferentiation to haemopoietic cells is not a normal property of neural stem cells. This, and all other similar work with adult neuronal stem cells, has been criticised on the grounds that considerable manipulation of the donor cell population has taken place because they all use cultured neurospheres. However, studies using mouse-chick chimaeras showed that the neurospheres could contribute to the liver, gastric mucosa, and mesonephric tubules. ${ }^{46}$

Plasticity can also take place in the opposite direction. When adult male mouse bone marrow was injected into lethally irradiated PU.1 knockout female mice, up to $4.6 \%$ of the CNS cells were found to be Y chromosome positive and to express neuronal markers. ${ }^{67}$

\section{Skin}

Similar to the gut, the skin has a high rate of cellular turnover, and therefore has the need for a resident population of stem cells. The human epidermis contains two types of proliferating keratinocytes: stem cells and transit amplifying cells. Although the exact identity of the stem cells in humans has not been ascertained, it has been suggested that they can be distinguished from the transit amplifying cells by their higher expression of $\alpha 2 \beta 1$ and $\alpha 3 \beta 1$ integrins ${ }^{68}$ Hair follicular stem cells are located in the bulge region of the follicle and are able to give rise to the various follicular cells, in addition to the interfollicular epidermis. ${ }^{69}$

The study by Krause et al found that approximately $2 \%$ of cytokeratin positive cells were positive for the Y chromosome 11 months after a male bone marrow transplant. ${ }^{44}$ They were found predominantly in the bulge, but also in the epidermis. Stem cells isolated from the dermis of juvenile and adult rodent skin have been shown to differentiate in culture into neural cells (neurones and glia) and mesodermal cells (smooth muscle cells and adipocytes).$^{70}$ Similar cells were isolated from the human scalp, and were able to produce neurone specific proteins.

Human adult MSCs have been administered intraperitoneally into fetal sheep at the same time as wounds were created by tail clipping. Human cells of fibroblastic morphology were subsequently found within the dermis and dermal appendages. ${ }^{71}$ Thus, circulating MSCs seem to have the potential to take part in the process of skin repair.

\section{Skeletal muscle}

The local stem cells for skeletal muscle are thought to reside between the sarcolemma and the basal lamina of the muscle fibre and are known as satellite cells. Cells isolated and cultured from mouse skeletal muscle (possibly akin to satellite cells) were injected into mice, together with distinguishable bone marrow, and were thought to have the capability of producing a full range multilineage engraftment of all major adult blood lineages. ${ }^{72}$ However, McKinney-Freeman et al later proposed that the muscle derived haemopoietic stem cells were in fact derived from the haemopoietic system (as a result of the presence of haemopoietic cells in the muscle), and not transdifferentiation of myogenic stem cells. ${ }^{73}$ Ferrari and colleagues ${ }^{15}$ have shown that cells from whole bone marrow are capable of migrating into damaged skeletal muscle and within weeks contribute nuclei to the newly formed muscle fibres. After transplanting both adherent and non-adherent cell subpopulations, both were shown to be capable of generating skeletal muscle myocytes.

In the clinical setting it has been shown in a mouse model of muscular dystrophy, the mdx mouse, that marrow derived skeletal muscle cells developed and expressed normal dystrophin in up to $10 \%$ of muscle fibres 12 weeks after a bone marrow transplant from wild-type animals. ${ }^{74}$

\section{Bone}

Intravenous injection of male mouse bone marrow into female non-irradiated hosts is able to contribute, albeit at a low frequency, to the formation of the long bones. ${ }^{75}$ Once engrafted the cells were able to produce bone, before terminally differentiating into osteocytes. Hou et al have utilised the osteoblast specificity of the osteocalcin promoter to confine the expression of specific genes to bone. ${ }^{76}$ They transplanted adherent bone marrow cells containing the gene promoter via the intravenous route and their presence was detected in various tissues of the host, whereas the expression of the transgene was found only in the osteoblasts and osteocytes. This technique has possible wide ranging therapeutic implications.

Three infants with osteogenesis impefecta were given whole bone marrow grafts after ablation of their bone marrow. ${ }^{77}$ After three months, all three children showed an improvement in their total body bone mineral content, associated with improved growth and fewer fractures.

\section{Cartilage}

Isolated and expanded MSCs can be induced by dexamethasone and transforming growth factor $\beta 3$ to secrete an extracellular matrix incorporating type II collagen, aggrecan, and anionic proteoglycans, features of chondroid differentiation. ${ }^{78}$ Human MSCs injected intraperitoneally into fetal sheep contribute to articular cartilage chondrocytes. ${ }^{71}$

\section{STEM CELLS AND CANCER}

Scientific knowledge gained from the field of cancer research has sometimes shed light on stem cell mechanics, as studies of stem cell biology have given valuable insight into the origin of cancer, and will hopefully one day impact on the treatment of this disease.

There are many links between stem cells and neoplasia. Because stem cells persist and divide over the lifespan of an individual, they are seemingly much more likely than progenitor cells to be able to accumulate the requisite number of mutations that cause neoplasia. ${ }^{79}$ Stem cells also have the ability to renew themselves, and cancer can be thought of as a disease of dysregulated self renewal. Therefore, it is highly probable that there are common mechanisms for achieving these processes (for example, telomerase activity) (fig 7). Other candidates implicated in both normal stem cell homeostasis and cancer include Wnt and Bcl-2. Indeed, the prevention of apoptosis by enforced expression of Bcl-2 results in increased numbers of HSCs in vivo, suggesting that HSCs may rely on programmed cell death to regulate their number ${ }^{80}{ }^{81}$ Wnt proteins (which contribute to cancer when dysregulated) are expressed in the bone marrow, suggesting they may also have a part to play in HSC homeostasis. Soluble 

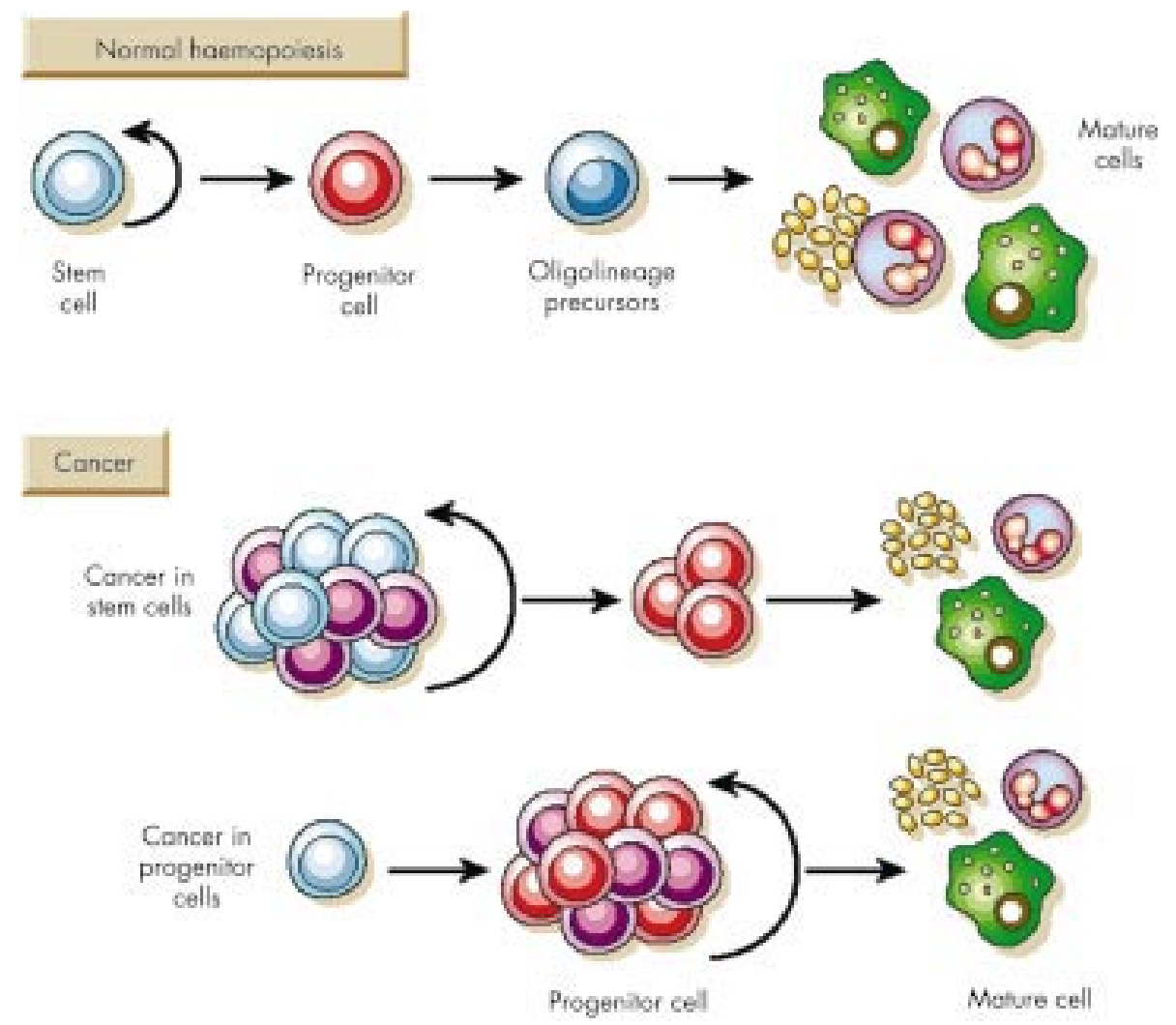

Figure 7 Comparison of self renewal during haemopoietic stem cell development and leukaemic transformation. Because of their high level of self renewal, stem cells are particularly good targets for leukaemic transformation. Unlike normal haemopoiesis, where signalling pathways that have been proposed to regulate self renewal are tightly regulated (top), during transformation of stem cells, the same mechanisms may be dysregulated to allow uncontrolled self renewal (middle). Furthermore, if the transformation event occurs in progenitor cells, it must endow the progenitor cell with the self renewal properties of a stem cell, because these progenitors would otherwise differentiate (bottom). (Reprinted by permission from Nature. ${ }^{85}$ Copyright (2001), Macmillan Publishers Ltd.)

Wnt proteins from conditioned supernatants have been shown to influence the proliferation of haemopoietic cells from mouse fetal liver and human bone marrow. ${ }^{82}{ }^{83}$ Gat et al showed that activation of the Wnt signalling pathway in transgenic mice in epidermal stem cells led to tumour formation. ${ }^{84}$ The Tcf-4 protein is a partner protein for $\beta$-catenin (a downstream activator of the Wnt signalling pathway) and the heterodimer transactivates several genes involved in cell cycling. Activation of this pathway is one of the earliest abnormalities in colonic carcinogenesis. In addition, it has been shown that mice lacking the gene Tcf712 (which encodes Tcf-4) fail to maintain proliferative compartments in the nascent crypt regions between the villi, implying that the genetic programme controlled by Tcf- 4 is responsible for the development of the crypt stem cells in the normal small intestine. ${ }^{12}$

Metaplasia is a change in tissue differentiation and is usually associated with chronic damage and regeneration. It would be logical to suppose that this switch occurs at the level of the stem cell-a type of plasticity? It is thought that it is the change in local environment that provides the stimulus for the differentiation switch to take place, possibly through epigenetic mechanisms. Indeed, there are many examples of neoplastic development occurring within a metaplastic field (for example, squamous carcinoma from squamous metaplasia of the respiratory airways and oesophageal adenocarcinoma from Barrett's metaplasia).

\section{CLINICAL IMPLICATIONS}

It is hoped that further research into gene therapy of human stem cells during development and differentiation may culminate in the successful correction of a defective gene in a human stem cell. Candidates for such therapy include cystic fibrosis and the haemoglobinopathies. Because HSCs are clearly capable of targeting solid organs and can be isolated prospectively using a combination of surface markers, they are one of the most promising candidates for the correction of single gene defects. HSCs have also been made resistant to cytotoxic drugs by using retroviral transduction to insert the multidrug resistant gene (MDRI), ${ }^{86}$ with the aim of limiting the myelosuppressive effects of standard chemotherapy regimens. Cancer is another area where manipulation of stem cells is vital. Several methods have been used, including the introduction of suicide genes into malignant stem cells. Examples of this are herpes simplex thymidine kinase and/or cytosine deaminase, which could be used in combination with oncolytic viruses that could theoretically be able to reach and destroy widespread metastases. ${ }^{87} 88$ Gene transfer of major histocompatibility complex genes across species may be used to induce tolerance to xenogenic solid organs, should stem cells from another species be used as a source of engineered tissue.

$$
\begin{aligned}
& \text { "It is hoped that further research into gene therapy of } \\
& \text { human stem cells during development and } \\
& \text { differentiation may culminate in the successful } \\
& \text { correction of a defective gene in a human stem cell" }
\end{aligned}
$$

As the research in tissue engineering advances, so the list of potential tissues that can be engineered grows. Currently, epithelial surfaces such as skin, cornea, and mucosal membranes, in addition to skeletal tissues, can all be engineered using stem cells. Some of the developing techniques rely on matrices on which the tissue grows, but others need no such framework (fig 8). 
A

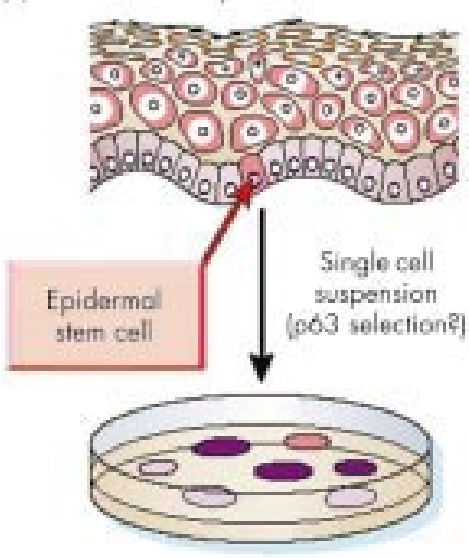

Ex vivo exponsion conditions to maintain 'holoclones' [stem cell population]

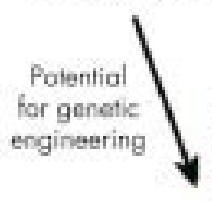

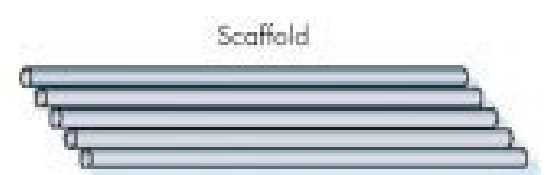

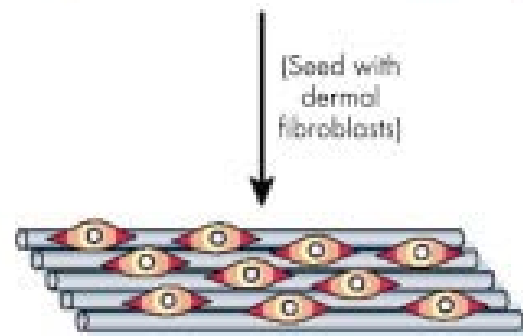

Dermol substitute

B

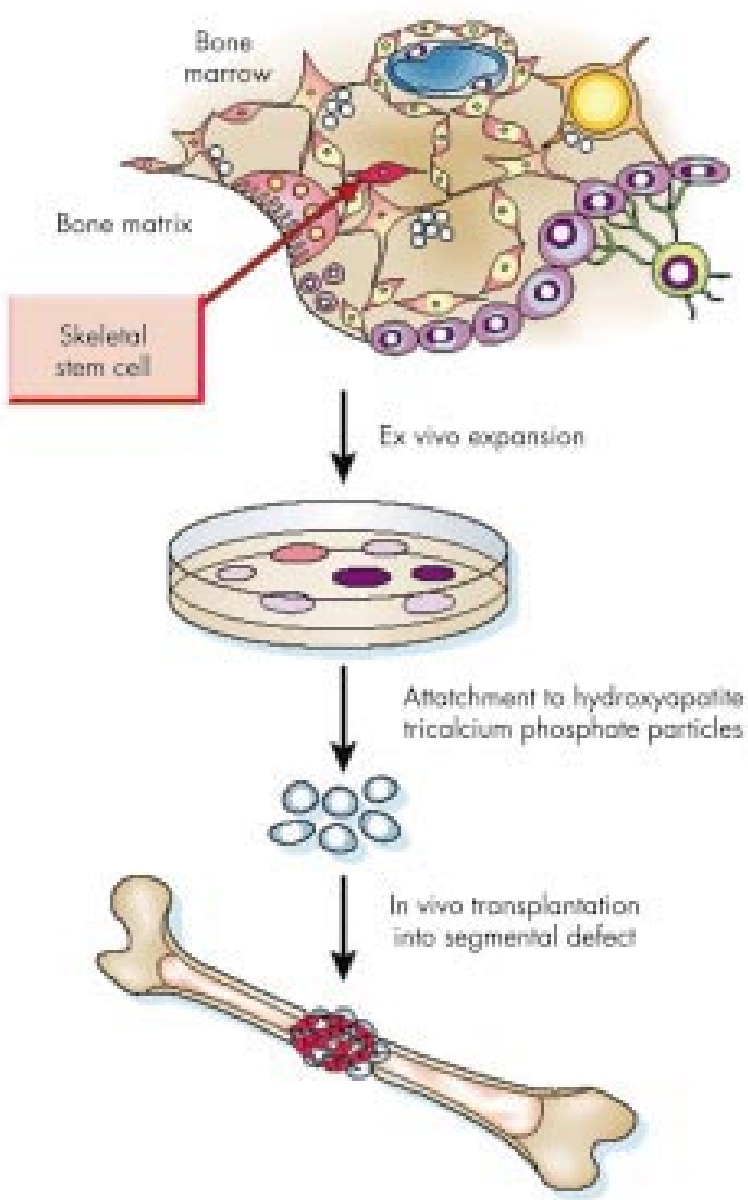

Figure 8 Some potential clinical uses of stem cells. Regeneration of two dimensional (skin) and three dimensional (bone) tissues using stem cells. (A) Skin autografts are produced by culturing keratinocytes (which may be sorted for p63, the recently described epidermal stem cell marker) under appropriate conditions not only to generate an epidermal sheet, but also to maintain the stem cell population (holoclones). The epidermal sheet is then placed on top of a dermal substitute comprising devitalised dermis or bioengineered dermal substitutes seeded with dermal fibroblasts. Such two dimensional composites, generated ex vivo, completely regenerate full thickness wounds. (B) Bone regeneration requires ex vivo expansion of bone marrow derived skeletal stem cells and their attachment to three dimensional scaffolds, such as particles of a hydroxyapatite/ tricalcium phosphate ceramic. This composite can be transplanted into segmental defects and will subsequently regenerate an appropriate three dimensional structure in vivo. (Reprinted by permission from Nature. ${ }^{89}$ Copyright (2001), Macmillan Publishers Ltd.)

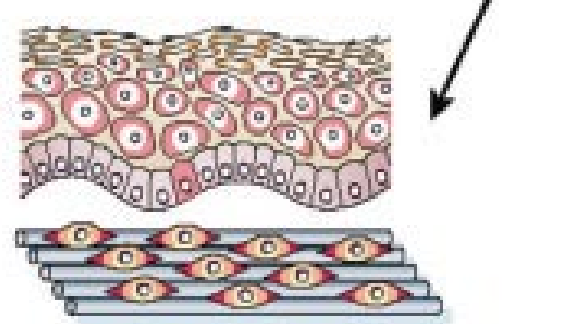

Full thickness skin wounds

(2001), Macmillan Publishers tid.

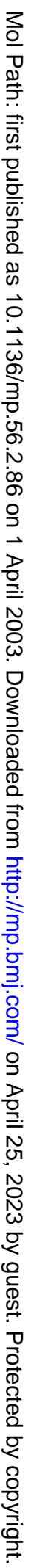




\section{Take home messages}

- The transdifferentiation of adult stem cells does occur although it is usually a rare event and normally occurs in the context of severe organ damage

- For transdifferentiation to make a meaningful contribution to tissue replacement a strategy needs to be devised that promotes clonal expansion of the cells in their new environment

- To date, this has only been demonstrated in one or two cases

Stem cell transplants could be used to treat a wide variety of pathologies, especially ones affecting specific cells types such as cardiomyocytes, dopaminergic neurones, and islet $\beta$ cells that have been destroyed. There is anecdotal evidence that patients with myocardial infarction recover faster when autologous HSCs are injected directly into the heart. Fetal midbrain is currently being used in a trial setting in the treatment of Parkinson's disease, and pancreatic duct cells are being used in the treatment of diabetes.

Haemopoietic cell transplants have been used for their additional ability to generate a specific immunological response in the recipient. The proliferating lymphoid cells derived from the donor stem cells have been used to seek out and destroy remaining tumour cells (graft versus leukaemia effect) and also to clear host cells of persisting viral infections, such as Epstein Barr virus. Elucidating the crucial differences in the subsets of lymphocytes responsible for the graft versus leukaemia effect and graft versus host disease is currently the subject of much research.

\section{CONCLUSIONS}

Although great leaps have been taken in the world of stem cell research, many questions remain unanswered. It will take further work to persuade the sceptics that certain adult stem cell populations really are as malleable as some advocates would have us believe. They will have to demonstrate unequivocally that the engrafted cells cannot only clonally expand within their new location, but also that they take on the function of the cells of their new organ of residence; moreover, issues such as cell fusion have to be resolved. It is vital before we put these cells into humans in a clinical setting that we know more about how they reach their ultimate status, and indeed establish that this state really is final and stable. Much of this is probably dependent on the interaction of local cytokines and the extracellular matrix. Importantly, engraftment and clonal expansion are known to be infrequent and slow events, ${ }^{51}$ and if the process is to be useful clinically, techniques must be established to enhance both these factors.

The clinical applications of stem cell research are virtually without limit. Further breakthroughs in this field will probably yield not only new forms of treatment, but provide a greater understanding of some important pathological mechanisms. The combination of stem cell transplantation and gene therapy is a particularly exciting one. However, as the boundaries are pushed back it is important to take into account the complex ethical, political, and religious issues that surround the subject matter.

\section{Authors' affiliations}

S L Preston, N A Wright, Department of Histopathology, Barts and the London School of Medicine and Dentistry, Turner Street, London El 2AD, UK

N C Direkze, R Poulsom, Department of Histopathology, Cancer Research UK, 44 Lincoln's Inn Fields, London WC2A 3PX, UK M Allison, S J Forbes, Imperial College, Hammersmith Campus, Du Cane Road, London W12 ONN, UK

\section{REFERENCES}

1 Thomson JA, Itskovitz-Eldor J, Shapiro SS, et al. Embryonic stem cell lines derived from human blastocysts. Science 1998:282:1145-7.

2 Lagasse E, Connors H, Al-Dhalimy M, et al. Purified hematopoietic stem cells can differentiate into hepatocytes in vivo. Nat Med 2000;6: 1229-34

3 Weissman IL. Translating stem and progenitor cell biology to the clinic: barriers and opportunities. Science 2000;287: 1442-6.

4 Heslop HE, Rooney CM, Rill DR, et al. Use of gene marking in bone marrow transplantation. Cancer Detect Prev 1996;20:108-13.

5 Bonnet D. Haematopoietic stem cells 1. J Pathol 2002; 197:430-40.

6 Cairns J. Somatic stem cells and the kinetics of mutagenesis and carcinogenesis. Proc Natl Acad Sci U S A 2002;99: 10567-70.

7 Quesenberry PJ, Becker PS. Stem cell homing: rolling, crawling, and nesting. Proc Natl Acad Sci U S A 1998;95:15155-7.

8 Cross MA, Enver T. The lineage commitment of haemopoietic progenitor cells. Curr Opin Genet Dev 1997;7:609-13.

9 Jensen UB, Lowell S, Watt FM. The spatial relationship between stem cells and their progeny in the basal layer of human epidermis: a new view based on whole-mount labelling and lineage analysis. Development 1999; 126:2409-18.

10 Spradling A, Drummond-Barbosa D, Kai T. Stem cells find their niche. Nature 2001;414:98-104.

11 Bierknes $M$, Cheng $\mathrm{H}$. Clonal analysis of mouse intestinal epithelial progenitors. Gastroenterology 1999;116:7-14.

12 Korinek V, Barker N, Moerer P, et al. Depletion of epithelial stem-cell compartments in the small intestine of mice lacking Tcf-4. Nat Genet 1998;19:379-83.

13 Nishimura EK, Jordan SA, Oshima H, et al. Dominant role of the niche in melanocyte stem-cell fate determination. Nature 2002;416:854-60.

14 Holden C, Vogel G. Stem cells. Plasticity: time for a reappraisal? Science 2002;296:2126-9.

15 Ferrari G, Cusella-De Angelis G, Coletta M, et al. Muscle regeneration by bone marrow-derived myogenic progenitors. Science 1998;279: 1528-30.

16 Alison MR, Poulsom R, Jeffery R, et al. Hepatocytes from non-hepatic adult stem cells. Nature 2000;406:257.

17 Eglitis MA, Mezey E. Hematopoietic cells differentiate into both microglia and macroglia in the brains of adult mice. Proc Natl Acad Sci U S A 1997;94:4080-5.

18 Orlic D, Kajstura J, Chimenti S, et al. Bone marrow cells regenerate infarcted myocardium. Nature 2001:410:701-4.

19 Poulsom R, Forbes SJ, Hodivala-Dilke K, et al. Bone marrow contributes to renal parenchymal turnover and regeneration. J Pathol 2001;195:229-35.

20 Biornson C, Rietze R, Reynolds B, et al. Turning brain into blood: a hematopoietic fate adopted by neural stem cells in vivo. Science 1999;283:534-7

21 Anderson DJ, Gage FH, Weissman IL. Can stem cells cross lineage boundaries? Nat Med 2001;7:393-5.

22 Terada N, Hamazaki T, Oka M, et al. Bone marrow cells adopt the phenotype of other cells by spontaneous cell fusion. Nature 2002;41 6:542-5

23 Ying QL, Nichols J, Evans EP, et al. Changing potency by spontaneous fusion. Nature 2002;416:545-8

24 Srivatsa B, Srivatsa S, Johnson KL, et al. Microchimerism of presumed fetal origin in thyroid specimens from women: a case-control study. Lancet $2001 ; 358: 2034-8$.

25 Jiang $Y$, Jahagirdar BN, Reinhardt RL, et al. Pluripotency of mesenchymal stem cells derived from adult marrow. Nature 2002;418:41-9.

26 Rafii S, Shapiro F, Rimarachin J, et al. Isolation and characterization of human bone marrow microvascular endothelial cells: hematopoietic progenitor cell adhesion. Blood 1994;84:10-9.

27 Hall F, Han B, Kundu R, et al. Phenotypic differentiation of tgf-beta l-responsive pluripotent premesenchymal prehematopoietic progenitor (p4 stem) cells from murine bone marrow. J Hematother Stem Cell Res 2001;10:261-71.

28 Kessinger A, Armitage JO, Smith DM, et al. High-dose therapy and autologous peripheral blood stem cell transplantation for patients with lymphoma. Blood 1989;74:1260-5.

29 Broxmeyer HE, Douglas GW, Hangoc G, et al. Human umbilical cord blood as a potential source of transplantable hematopoietic stem/progenitor cells. Proc Natl Acad Sci U S A 1989;86:3828-32.

30 Morrison SJ, Hemmati HD, Wandycz AM, et al. The purification and characterization of fetal liver hematopoietic stem cells. Proc Natl Acad Sci U S A 1995; 92: 10302-6.

31 Peled A, Petit I, Kollet O, et al. Dependence of human stem cell engraftment and repopulation of NOD/SCID mice on CXCR4. Science 1999;283:845-8.

32 Levesque JP Ty, Nilsson SK, et al. Mobilisation of hemopoietic progenitor cells into peripheral blood is associated with VCAMproteolytic cleavage in the bone marrow [abstract]. Blood 2000;96/suppl 1):221 a

33 Tomita S, Li R, Weisel R, et al. Autologous transplantation of bone marrow cells improves damaged heart function. Circulation 1999;100(suppl 19):11247-56.

34 Azizi S, Stokes D, Augelli B, et al. Engraftment and migration of human bone marrow stromal cells implanted in the brains of albino rats-similarities to astrocyte grafts. Proc Natl Acad Sci U S A 1998;95:3908-13. 
35 Lin Y, Weisdorf D, Solovey A, et al. Origins of circulating endothelial cells and endothelial outgrowth from blood. J Clin Invest 2000; 105:71-7

36 Asahara T, Murohara T, Sullivan A, et al. Isolation of putative progenitor endothelial cells for angiogenesis. Science 1997;275:964-7.

37 Williams G, Krajewski C, Dagher F, et al. Host repopulation of endothelium. Transplant Proc 1971;ill:869-72.

38 Williams G, Alvarez C. Host repopulation of the endothelium in allografts of kidneys and aorta. Surg Forum 1969;20:293-4.

39 Kocher A Schuster M Szabolcs M et al. Neovascularization of ischemic myocardium by human bone-marrow-derived angioblasts prevents cardiomyocyte apoptosis, reduces remodeling and improves cardiac function. Nat Med 2001;7:430-6.

40 Malouf N, Coleman W, Grisham J, et al. Adult-derived stem cells from the liver become myocytes in the heart in vivo. Am J Pathol 2001;158:1929-35

41 Jackson KA, Majka SM, Wang H, et al. Regeneration of ischemic cardiac muscle and vascular endothelium by adult stem cells. J Clin Invest 2001; 107:1395-402.

42 Strauer BE, Brehm M, Zeus $T$, et al. [Intracoronary, human autologous stem cell transplantation for myocardial regeneration following myocardial infarction]. Dtsch Med Wochenschr 2001;126:932-8.

43 Boers JE, Ambergen AW, Thunnissen FB. Number and proliferation of clara cells in normal human airway epithelium. Am J Respir Crit Care Med 1999;159(5 Pt 1):1585-91.

44 Krause D, Theise N, Collector $M$, et al. Multi-organ, multi-lineage engraftment by a single bone marrow-derived stem cell. Cell 2001;105:369-77

45 Brittan $M$, Hunt $T$, Jefferey $R$, et al. Bone marrow derivation of pericryptal myofibroblasts in the mouse and human small intestine and colon. Gut 2002;50:752-7.

46 Clarke D, Johansson C, Wilbertz J, et al. Generalized potential of adult neural stem cells. Science 2000;288:1660-3

47 Suzuki A, Zheng YW, Kaneko S, et al. Clonal identification and characterization of self-renewing pluripotent stem cells in the developing liver. J Cell Biol 2002;156:173-84.

48 Alison MR, Golding MH, Sarraf CE. Pluripotential liver stem cells: facultative stem cells located in the biliary tree. Cell Prolif 1996;29:373-402.

49 Petersen B, Bowen W, Patrene K, et al. Bone marrow as a potential source of hepatic oval cells. Science 1999;284:1168-70.

50 Theise N, Nimmakalayu M, Gardner R, et al. Liver from bone marrow in humans. Hepatology 2000;32:11-16.

51 Wang X, Montini E, Al-Dhalimy M, et al. Kinetics of liver repopulation after bone marrow transplantation. Am J Pathol 2002:161:565-74.

52 Bonner-Weir S, Taneja M, Weir GC, et al. In vitro cultivation of human islets from expanded ductal tissue. Proc Natl Acad Sci U S A 2000;97:7999-8004.

53 Ramiya VK, Maraist M, Arfors KE, et al. Reversal of insulin-dependent diabetes using islets generated in vitro from pancreatic stem cells. Nat Med 2000;6:278-82

54 Krakowski ML, Kritzik MR, Jones EM, et al. Pancreatic expression of keratinocyte growth factor leads to differentiation of islet hepatocytes and proliferation of duct cells. Am J Pathol 1999;154:683-91.

55 Wang $X$, Al-Dhalimy $M$, Lagasse $E$, et al. Liver repopulation and correction of metabolic liver disease by transplanted adult mouse pancreatic cells. Am J Pathol 2001;158:571-9.

56 Grimm PC, Nickerson P, Jeffery J, et al. Neointimal and tubulointerstitial infiltration by recipient mesenchymal cells in chronic renal-allograft rejection. N Engl J Med 2001;345:93-7.

$57 \mathrm{Ng} \mathrm{Y}$, Huang T, Yang W, et al. Tubular epithelial-myofibroblast transdifferentiation in progressive tubulointerstitial fibrosis in $5 / 6$ nephrectomized rats. Kidney Int 1998;54:864-76.

58 Kalyani AJ, Piper D, Mujtaba T, et al. Spinal cord neuronal precursors generate multiple neuronal phenotypes in culture. J Neurosci 1998; 18:7856-68

59 Kalyani A, Hobson K, Rao MS. Neuroepithelial stem cells from the embryonic spinal cord: isolation, characterization, and clonal analysis. Dev Biol 1997; 186:202-23.

60 Gage FH. Mammalian neural stem cells. Science 2000;287:1433-8.

61 McKay R. Stem cells in the central nervous system. Science 1997;276:66-71.

62 Rao MS. Multipotent and restricted precursors in the central nervous system. Anat Rec 1999;257:137-48.
63 Shihabuddin LS, Ray J, Gage FH. Stem cell technology for basic science and clinical applications. Arch Neurol 1999;56:29-32.

64 Palmer T, Schwartz P, Taupin P, et al. Progenitor cells from human brain after death. Nature 2001;411:42-3.

65 Shihbuddin L, Horner P, Ray J, et al. Adult spinal cord stem cells generate neurons after transplantation in the adult dentate gyrus. J Neurosci 2000;20:8727-35.

66 Morshead CM, Benveniste P, Iscove NN, et al. Hematopoietic competence is a rare property of neural stem cells that may depend on genetic and epigenetic alterations. Nat Med 2002;8:268-73.

67 Mezey E, Chandross K, Harta G, et al. Turning blood into brain: cells bearing neuronal antigens generated in vivo from bone marrow. Science 2000;290: 1779-82.

68 Jones PH, Harper S, Watt FM, et al. Stem cell patterning and fate in human epidermis. Cell 1995;80:83-93.

69 Taylor G, Lehrer MS, Jensen PJ, et al. Involvement of follicular stem cells in forming not only the follicle but also the epidermis. Cell 2000;102:451-61.

70 Toma JG, Akhavan M, Fernandes KJ, et al. Isolation of multipotent adult stem cells from the dermis of mammalian skin. Nat Cell Biol $2001 ; 3: 778-84$.

71 Liechty K, MacKenzie T, Shaaban A, et al. Human mesenchymal stem cells engraft and demonstrate site-specific differentiation after in utero transplantation in sheep. Nat Med 2000;6:1282-6.

72 Jackson K, Mi T, Goodell M. Hematopoietic potential of stem cells isolated from murine skeletal muscle. Proc Natl Acad Sci U S A 1999:96:14482-6.

73 McKinney-Freeman SL, Jackson KA, Camargo FD, et al. Muscle-derived hematopoietic stem cells are hematopoietic in origin. Proc Natl Acad Sci U S A 2002;99:1341-6.

74 Gussoni E, Soneoka Y, Strickland CD, et al. Dystrophin expression in the $\mathrm{mdx}$ mouse restored by stem cell transplantation. Nature 1999:401:390-4.

75 Nilsson S, Dooner $M$, Weier $\mathrm{H}$, et al. Cells capable of bone production engraft from whole bone marrow transplants in nonablated mice. J Exp Med 1999;189:729-34.

76 Hou Z, Nguyen Q, Frenkel B, et al. Osteoblast-specific gene expression after transplantation of marrow cells: implications for skeletal gene therapy. Proc Natl Acad Sci U S A 1999;96:7294-9.

77 Horwitz E, Prockop D, Fitzpatrick L, et al. Osteogenesis imperfecta calls for caution. Nat Med 1999:5:466-7.

78 Mackay A, Beck S, Murphy J, et al. Chondrogenic differentiation of cultured human mesenchymal stem cells from marrow. Tissue Eng 1998;4:415-28.

79 Nowell PC. The clonal evolution of tumor cell populations. Science 1976:194:23-8

80 Domen J, Gandy KL, Weissman IL. Systemic overexpression of BCL-2 in the hematopoietic system protects transgenic mice from the consequences of lethal irradiation. Blood 1998;91:2272-82.

81 Domen J, Weissman IL. Hematopoietic stem cells need two signals to prevent apoptosis; BCL-2 can provide one of these, Kitl/c-Kit signaling the other. J Exp Med 2000;192:1707-18

82 Austin TW, Solar GP, Ziegler FC, et al. A role for the Wnt gene family in hematopoiesis: expansion of multilineage progenitor cells. Blood 1997:89:3624-35.

83 Van Den Berg DJ, Sharma AK, Bruno E, et al. Role of members of the Wnt gene family in human hematopoiesis. Blood 1998;92:3189-202

84 Gat U, DasGupta R, Degenstein L, et al. De novo hair follicle morphogenesis and hair tumors in mice expressing a truncated beta-catenin in skin. Cell 1998;95:605-14.

85 Reya T, Morrison SJ, Clarke MF, et al. Stem cells, cancer, and cancer stem cells. Nature 2001;414:105-11

86 Cowan KH, Moscow JA, Huang H, et al. Paclitaxel chemotherapy after autologous stem-cell transplantation and engraftment of hematopoietic cells transduced with a retrovirus containing the multidrug resistance complementary DNA (MDR 1) in metastatic breast cancer patients. Clin Cancer Res 1999;5:1619-28.

87 Anderson WF. Gene therapy scores against cancer. Nat Med 2000;6:862-3.

88 Brenner MK. Gene transfer in haematological malignancy. Ann Med 1996;28:491-7.

89 Bianco P, Robey PG. Stem cells in tissue engineering. Nature $2001 ; 414: 118-21$ 